\title{
Distribution of meteoric smoke - sensitivity to microphysical properties and atmospheric conditions
}

\author{
L. Megner ${ }^{1}$, M. Rapp ${ }^{1,2}$, and J. Gumbel ${ }^{1}$ \\ ${ }^{1}$ Department of Meteorology, Stockholm University, Stockholm, Sweden \\ ${ }^{2}$ Leibniz-Institute of Atmospheric Physics, Kühlungsborn, Germany
}

Received: 4 April 2006 - Published in Atmos. Chem. Phys. Discuss.: 27 June 2006

Revised: 21 September 2006 - Accepted: 28 September 2006 - Published: 4 October 2006

\begin{abstract}
Meteoroids entering the Earth's atmosphere experience strong deceleration and ablate, whereupon the resulting material is believed to re-condense to nanometre-size "smoke particles". These particles are thought to be of great importance for many middle atmosphere phenomena, such as noctilucent clouds, polar mesospheric summer echoes, metal layers, and heterogeneous chemistry. The properties and distribution of meteoric smoke depend on poorly known or highly variable factors such as the amount, composition and velocity of incoming meteoric material, the efficiency of coagulation, and the state and circulation of the atmosphere. This work uses a one-dimensional microphysical model to investigate the sensitivities of meteoric smoke properties to these poorly known or highly variable factors. The resulting uncertainty or variability of meteoric smoke quantities such as number density, mass density, and size distribution are determined. It is found that the two most important factors are the efficiency of the coagulation and background vertical wind. The seasonal variation of the vertical wind in the mesosphere implies strong global and temporal variations in the meteoric smoke distribution. This contrasts the simplistic picture of a homogeneous global meteoric smoke layer, which is currently assumed in many studies of middle atmospheric phenomena. In particular, our results suggest a very low number of nanometre-sized smoke particles at the summer mesopause where they are thought to serve as condensation nuclei for noctilucent clouds.
\end{abstract}

\section{Introduction}

Meteoric material reaching the Earth's ablates in the 80$100 \mathrm{~km}$ region and is believed to re-condense into tiny socalled "smoke particles" (Hunten et al., 1980). These parti-

Correspondence to: L. Megner

(linda@misu.su.se) cles are especially important in the middle atmosphere where dust sources from below are small. The smoke particles are thought to play a major role in a host of middle atmospheric phenomena, such as noctilucent clouds, polar mesospheric summer echoes, metal layers, and heterogeneous chemistry controlling key species such as water vapour.

Noctilucent clouds and polar mesospheric summer echoes are both a direct consequence of the presence of ice particles (e.g. Witt, 1969; Rapp and Lübken, 2004). The formation process of these ice-particles is however unclear. At water vapour partial pressures and temperatures of the mesopause region, homogeneous nucleation is considered unlikely such that pre-existing ice nuclei are deemed necessary (Keesee, 1989). Over the years, many different candidates for these nuclei have been proposed, such as ion clusters, sodium bicarbonate molecules, sulfate aerosols, soot particles, and meteoric smoke particles (see Rapp and Thomas, 2006 for a recent review). However, among these, meteoric smoke particles are considered the most likely candidate.

The ablated meteoric material also gives rise to metal atom ( $\mathrm{Na}, \mathrm{Fe}, \mathrm{K}, \mathrm{Mg}$ ) layers at altitudes of $80-100 \mathrm{~km}$ that easily can be detected by lidars. Plane (2004) shows that the diurnal variation of these layers only can be modelled satisfactorily by the inclusion of meteoric smoke particles serving as a sink for the metal species. Summers and Siskind (1999) discuss a local maximum in the water vapour distribution that occurs around $70 \mathrm{~km}$ altitude and cannot be explained applying conventional gas phase chemistry. They speculate that the reaction $\mathrm{O}+\mathrm{H}_{2} \rightarrow \mathrm{H}_{2} \mathrm{O}$ may occur on the surface of the smoke particles and explain the observed water maximum.

Despite the obvious scientific interest in these smoke particles, little is known about their actual properties. This lack of knowledge is mainly due to the complications involved in measurements at these altitudes where in situ studies only can be carried out using sounding rockets. Because of the difficulties in detecting neutral particles, measurements of nanometre-sized particles in the mesosphere are so far only

Published by Copernicus GmbH on behalf of the European Geosciences Union. 
available for the charged fraction of the total particle population (Schulte and Arnold, 1992; Gelinas et al., 1998; Croskey et al., 2001; Lynch et al., 2005; Rapp et al., 2005).

The term "smoke" has its origins in the space society and refers to particles formed by condensation or chemical reaction from molecularly dispersed matter (Gray, 1936). The first to describe the re-condensation of ablated meteoric material into smoke particles and to suggest their possible importance in the mesosphere were Rosinski and Snow (1961). In 1980, Hunten et al. (1980) performed a thorough study where they treated the ablation process, the coagulation, and the re-condensation to smoke particles and computed the smoke distribution. However, this smoke particle profile is by no means a given fact. On the contrary, many of the factors that determine the distribution were, and are to a large extent still today, poorly known. These factors include the amount of meteoric input, the height at which the ablation occurs and the density and coagulation efficiency of the smoke particles. Other factors, such as the state of the background atmosphere including winds and eddy diffusion, might be easier to determine, but are instead highly variable. The aim of this work is to investigate the sensitivities of the smoke particle system to these poorly known and highly variable factors and to determine the resulting uncertainties/variability of meteoric smoke quantities such as number density, mass density, and size distribution. The study is carried out using a 1-dimensional version of the CARMA model which is described in Sect. 3.

\section{Physical processes controlling the smoke production}

A schematic picture of the interactions believed to take place once meteoric material enters the earth's atmosphere is shown in Fig. 1.

Reaching the atmosphere the meteoroids experience a strong deceleration and an associated heating. As the temperature reaches the boiling temperature the meteor starts ablating. At which altitude this happens depends on the speed, size, entry angle and composition of the meteoroids (Ceplecha et al., 1998). Faster meteoroids experience stronger deceleration and therefore ablate at higher altitudes. The smaller meteoroids are more efficient at radiating the gained energy and can hence survive a stronger deceleration without the onset of ablation. The very smallest meteoroids $(<11.5 \mu \mathrm{g}$ at $12 \mathrm{~km} / \mathrm{s}$, see Hunten et al., 1980) never reach the boiling temperature and remain intact throughout the atmosphere. The slowest and largest meteoroids may not fully evaporate so that a residual meteorite remains, and less material is deposited in the atmosphere.

Subsequent steps in the evolution of smoke particles are highly uncertain: Following Rosinski and Snow (1961), Plane (2000) has argued that the concentration of the ablated material within the meteor trail is too low to compete with the outward diffusion of the meteor trail. Hence, a direct re-condensation of the meteoric material inside the trail on time scales of seconds to minutes is very unlikely. Instead, molecules and molecular clusters formed in the ablation process become "normal" actors in the mesospheric gas phase chemistry. Plane (2003) has recently pointed out that meteoric smoke particles are probably formed by polymerisation processes of metallic compounds and silicon oxides (all originating from meteoric ablation), since several of these species (particularly the metal mono-hydroxides, carbonates, and bi-carbonates) have large dipole moments. Nanometresized smoke particles are then thought to be subsequently formed by coagulation processes. As coagulation continues the particles are constantly subject to sedimentation as well as diffusion and advection by the wind.

How effective the coagulation is, depends on the probability of collision and the "sticking efficiency", i.e. the probability of sticking once having collided. The latter is a function of the roughness of the particle surface, the shape of the particle, as well as of atmospheric factors. We know too little about the smoke material to determine this efficiency but since the kinetic energy of the collisions is very small $\left(\sim 10^{-2} \mathrm{eV}\right)$ bounce-offs can be considered unlikely, and we assume a sticking efficiency of unity.

In the atmosphere, particles collide as a result of sedimentation speed differences, turbulent motion, intra-particle forces and Brownian motion. We shall here concentrate on the Brownian coagulation since the coagulation due to sedimentation speed differences and turbulent motion is negligible for particles smaller than $1 \mu \mathrm{m}$ in diameter (Fuchs, 1964) and that of inter-particular forces is difficult to estimate because of the unknown composition of smoke particles (this is dealt with in Sect. 4.4). The efficiency of the coagulation due to Brownian motion in the continuum regime for low Knudsen numbers is described by the Brownian coagulation kernel which for two particle populations $\mathrm{i}$ and $\mathrm{j}$ can be written as (Pruppacher and Klett, 1997)

$$
K_{i, j}=4 \pi\left(r_{i}+r_{j}\right)\left(D_{i}+D_{j}\right)
$$

Here $r_{i}, r_{j}$ are the radius of particles $\mathrm{i}$ and $\mathrm{j}$ respectively and $D_{i}, D_{j}$ are the corresponding diffusion coefficients, defined as

$D_{i}=\frac{k_{B} T}{6 \pi r_{i} \eta}\left(1+K n_{i}\left(A+B e^{-C / K n_{i}}\right)\right)$

where $k_{B}$ is Boltzmann's constant, $T$ the temperature, $\eta$ the viscosity of air, $K n$ the Knudsen number and $A, B$ and $C$ are corrections for particle resistance to motion (Millikan, 1923). In the upper parts of the mesosphere the air becomes so thin that continuum flow is no longer a good approximation. The model therefore uses an interpolation formula developed by Fuchs (1964) which covers both the free molecular regime and the continuum regime and simplifies to Eq. (2). See Jacobson et al. (1994) for further information. 


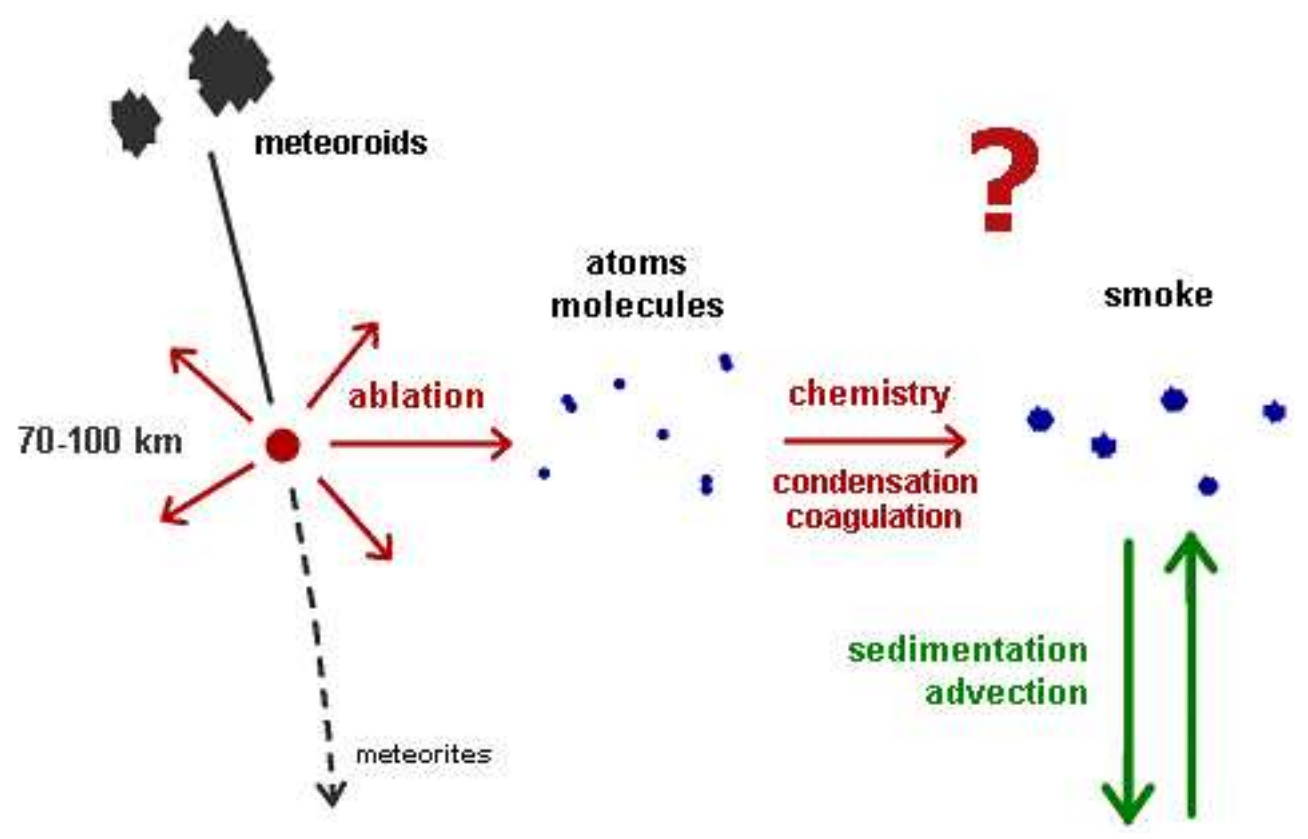

Fig. 1. Fate of the meteoric material entering the Earth's atmosphere.

Using expression 1 for the coagulation kernel the change in concentration $n_{k}$ of particles $k$ can be written (Pruppacher and Klett, 1997)

$\frac{\partial n_{k}}{\partial t}=\frac{1}{2} \sum_{i=1}^{k-1} K_{i, k-i} n_{i} n_{k-i}-n_{k} \sum_{i=1}^{\infty} K_{i, k} n_{i}$

The first term represent the production of k-particles by coagulation of smaller particles and the second term represent the k-particles that coagulate with others resulting in even bigger particles. The factor $1 / 2$ in the first time is due to the fact that only one k-particle is produced from every pair of colliding particles.

\section{The Community Aerosol and Radiation Model for At- mospheres: CARMA}

CARMA is a flexible three-dimensional microphysical model developed over the past 25 years, and has been applied to a wide variety of atmospheric problems both on Earth and on other planets. The applications range from studies of tropospheric cirrus clouds (e.g. Jensen et al., 2001), via polar stratospheric clouds (Toon et al., 1989), up to studies of noctilucent clouds (e.g. Rapp and Thomas, 2006). The model originated from a one dimensional stratospheric aerosol code developed by Turco et al. (1979) and Toon et al. (1979) that included both gas phase sulfur chemistry and aerosol microphysics. Later it was improved and extended to three dimensions as described by Toon et al. (1988).

The transport of particles is handled by an Eulerian transport scheme with a time step of $2000 \mathrm{~s}$. In order to properly handle vertical transport in a one-dimensional model, number densities of aerosol particles need to obey the continuity equation in the form (Jensen et al., 1989, their Eq. 1)

$\frac{\partial n}{\partial t}=w n\left(\frac{1}{\rho_{\text {air }}} \frac{\partial \rho_{\text {air }}}{\partial z}+\frac{1}{w} \frac{\partial w}{\partial z}\right)$

where $n$ is the number density of the transported species, $\rho_{\text {air }}$ is the density of air, and $w$ is the vertical velocity at which transport takes place. In the real 3-dimensional atmosphere this continuity approach can be interpreted in terms of a source/sink provided by the meridional circulation. Application of Eq. (4) also ensures that the model satisfies the hydrostatic equation.

The coagulation algorithm used in the model was developed by Toon et al. (1988) and Jacobson et al. (1994) where it is described in detail. The scheme allows the computation of coagulation among any number of particle types, each containing any number of substances. For the purpose of this study it is enough to treat meteoric smoke as one substance. This reduces the problem to only one particle type and thus greatly decreases the necessary computing power. The particles are treated as spherical and two colliding particles result in coalescence, so that another spherical particle is produced.

The model uses geometric bins where the particle volume assigned to one bin is equal to that of the previous bin multiplied by a constant factor, $V_{\mathrm{RAT}}\left(V_{\mathrm{RAT}}=1.6\right.$ in the current study), so that the volume of the $i$ th bin is

$v_{i}=v_{1} V_{\mathrm{RAT}}^{i-1}$

and the radius

$r_{i}=r_{1} V_{\mathrm{RAT}}^{(i-1) / 3}$ 

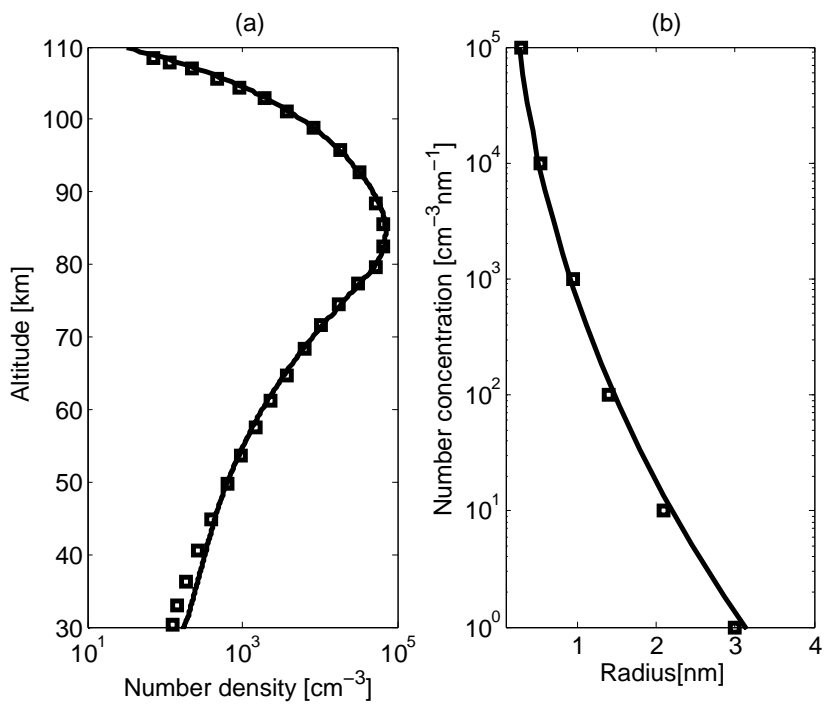

Fig. 2. Distributions of smoke particles as computed by the CARMA model using the same ablation profile and eddy diffusion as Hunten et al. (1980) (solid lines); (a) the total smoke particle number density as a function of altitude and (b) the size distribution at $90 \mathrm{~km}$. The original model results by Hunten et al. (1980) are shown as squares.

where $v_{1}$ and $r_{1}$ are the volume and particle radius corresponding to the first bin, respectively.

When two particles of volume $v_{i}$ and $v_{j}$ coagulate, the volume of the resulting particle is $V_{i j}=v_{i}+v_{j}$. The new volume is likely to be in-between the volumes of two model bins. To conserve volume it is therefore necessary to partition the new particle between the two bins $k$ and $k+1$. This is done by defining a volume fraction $f_{i, j, k}\left(0 \leq f_{i, j, k} \leq 1\right)$, of the new particle of size $V_{i j}$, that is partitioned to the two model bins $k$ and $k+1$ according to (Jacobson et al., 1994)

$f_{i, j, k}=\left(\frac{v_{k+1}-V_{i, j}}{v_{k+1}-v_{k}}\right) \frac{v_{k}}{V_{i, j}}$

This factor assumes geometrical bins and takes the size difference of the two bins into account.

For current purposes, we utilise the one-dimensional version of CARMA. This allows us to do many sensitivity studies in a reasonable amount of computation time. The model domain spans from 10 to $110 \mathrm{~km}$ altitude with a resolution of $0.25 \mathrm{~km}$. The meteor smoke particle size distributions are evaluated on radius grids consisting of 35 size bins between 0.2 to $40 \mathrm{~nm}$.

Finally, the piecewise parabolic method algorithm (Colela and Woodard, 1984) was used for both advection in the vertical and deposition growth (advection in particle radius space). For more information on the numerical aspects of the model, see Toon et al. (1988).

As an initial test of our simulations, we have tried to reproduce the results of Hunten et al. (1980). This means that we (a)

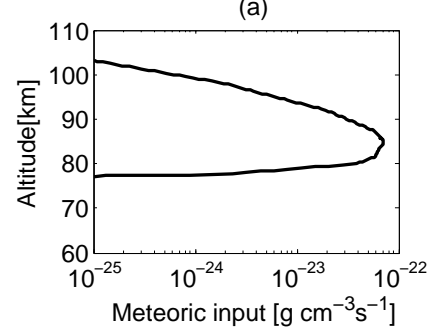

(c)

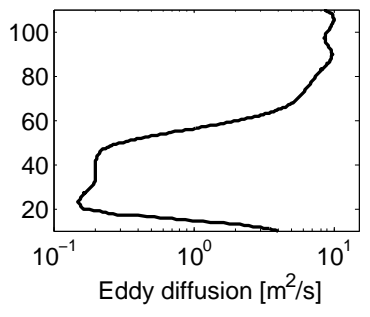

(b)

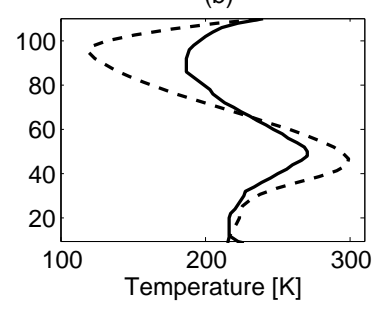

(d)

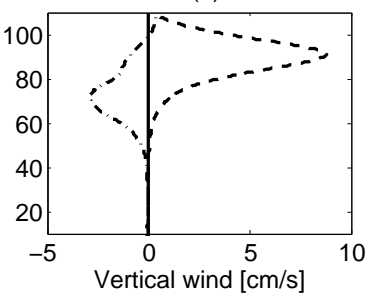

Fig. 3. Profiles used as model input, where the solid lines have been used to produce the reference profile; (a) the ablation profile, (b) temperature profiles (the solid line is from the U.S. standard atmosphere and the dashed line is a summer pofile from the CHEM2D model), (c) eddy diffusion profile, (d) vertical wind profiles for summer (dashed) and winter (dashed-dotted).

ran the model with the input parameters used in Hunten et al. (1980), i.e. their ablation profile, no vertical wind, an initial particle size of $0.2 \mathrm{~nm}$ in radius, Brownian coagulation, and eddy diffusion coefficients of $100 \mathrm{~m}^{2} / \mathrm{s}$ above $80 \mathrm{~km}$, which then decrease with an average scale height of $16 \mathrm{~km}$ below. Figure 2 shows the steady state number and size distribution of smoke particles as computed by the CARMA model (solid line) and the original distributions from Hunten et al.. Their results are well reproduced with our model setup.

\section{Sensitivity study}

\subsection{Reference profile}

We will now construct a reference case based on our current best estimates of the input variables. Then all further sensitivity studies will be compared to this case. We adopt the ablation profile from Hunten et al. (1980), see Fig. 3a, which corresponds to a meteoric mass influx of 44 metric tons/day. We assume that there is no substantial re-condensation of particles in the meteor trail because the outward diffusion of such trails is thought to be too rapid to maintain a supersaturated environment (see above). Hence, we start our calculations with initial particles sizes well within molecular dimensions, i.e., at a radius of $0.2 \mathrm{~nm}$. For the profile of vertical eddy diffusion-coefficients we use a seasonal and latitudinal average of the eddy diffusion-coefficients calculated with the two-dimensional chemical-dynamical CHEM2D model (Summers et al., 1997) (see Fig. 3). The temperatures and densities of the atmosphere are those of the U.S. standard 
(a)

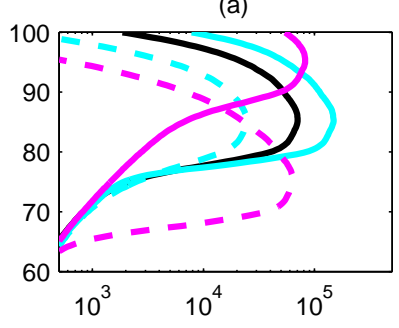

(d)

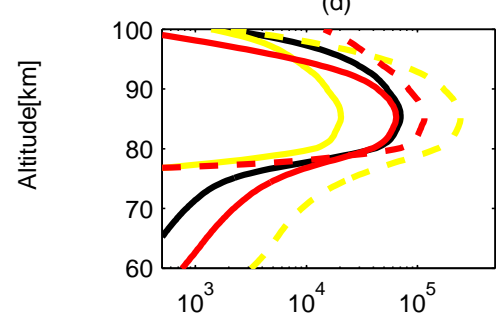

(g)

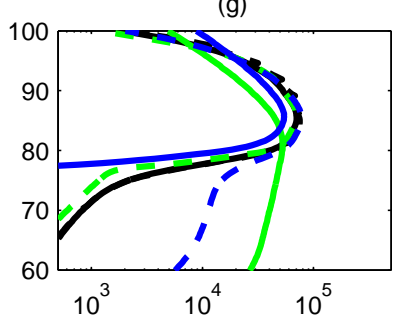

Number density $\left[\mathrm{cm}^{-3}\right]$
Meteoric influx and ablation

(b)

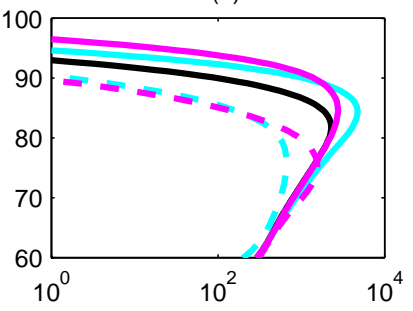

Particle microphysics

(e)

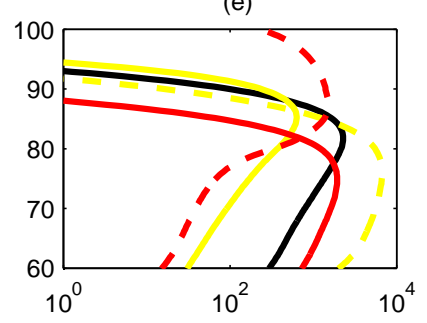

Atmospheric factors

(h)

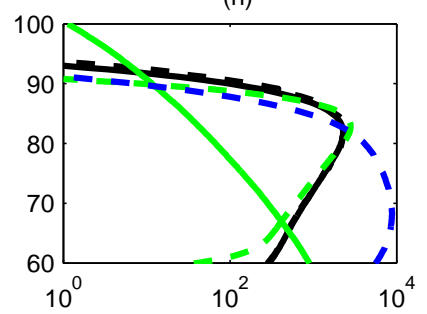

Number density $\left[\mathrm{cm}^{-3}\right]$

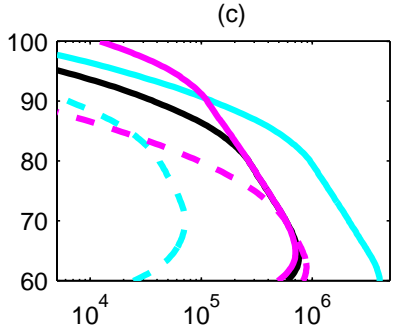

(f)

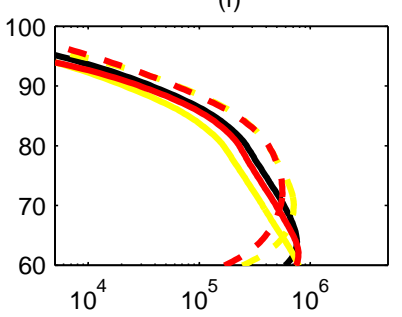

(i)

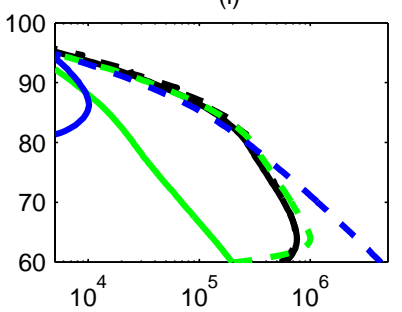

Mass density $\left[\mathrm{g} / \mathrm{cm}^{-3}\right]$

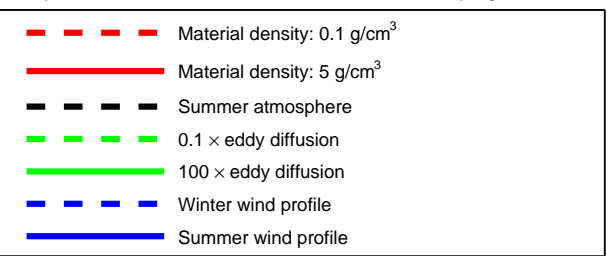

Fig. 4. Sensitivity of smoke the distribution as result of uncertainty and variability in the studied factors. The left hand panel (a, d, $\mathbf{g}$ ) shows the total number densities, the middle panel $(\mathbf{b}, \mathbf{e}, \mathbf{h})$ shows the number densities of particles bigger than $1 \mathrm{~nm}$ radius and the right hand panel $(\mathbf{c}, \mathbf{f}, \mathbf{i})$ shows the mass density. The top panel $(\mathrm{a}, \mathrm{b}, \mathrm{c})$ shows effects due to uncertainties in meteoric input, where the light blue lines represent the amount of input and the magenta lines the altitude of the ablation. The middle panel (d, e, f) shows the effects of internal smoke factors, yellow being the effects of coagulation uncertainties and red those of density/shape uncertainties. The bottom panel (g, h, i) shows the effect of atmospheric factors, dashed black line represents summer temperatures and densities, green line shows uncertainties due to eddy diffusion and blue lines show variations due to the vertical wind.

atmosphere, and the vertical wind is set to zero. Mass input according to the ablation profile is fed into the model at every time-step, and the model is run until an approximate steady state is reached. At altitudes of $\sim 80 \mathrm{~km}$, this happens after approximately 1 month, whereas at altitudes of $65 \mathrm{~km}$, three months are needed. In order to guarantee steady state conditions down to an altitude of $65 \mathrm{~km}$, our standard model integration time was hence chosen as three months.

The steady state profiles are shown as black lines in Figs. 4 and 5. The left hand panel of Fig. 4 shows the total num- ber densities, the middle panel shows the number densities of particles with radii larger than $1 \mathrm{~nm}$ radius, and the right hand panel shows the mass density. The limit of $1 \mathrm{~nm}$ radius has been chosen, since this is approximately the size the particles need to be in order to serve as condensation nuclei for noctilucent clouds (Keesee, 1989). This estimate is based on classical droplet-theory where the involved constants have been extrapolated to the thermodynamic conditions of the mesosphere. Rapp and Thomas (2006) conclude that our current knowledge on the ice nucleation process under the 


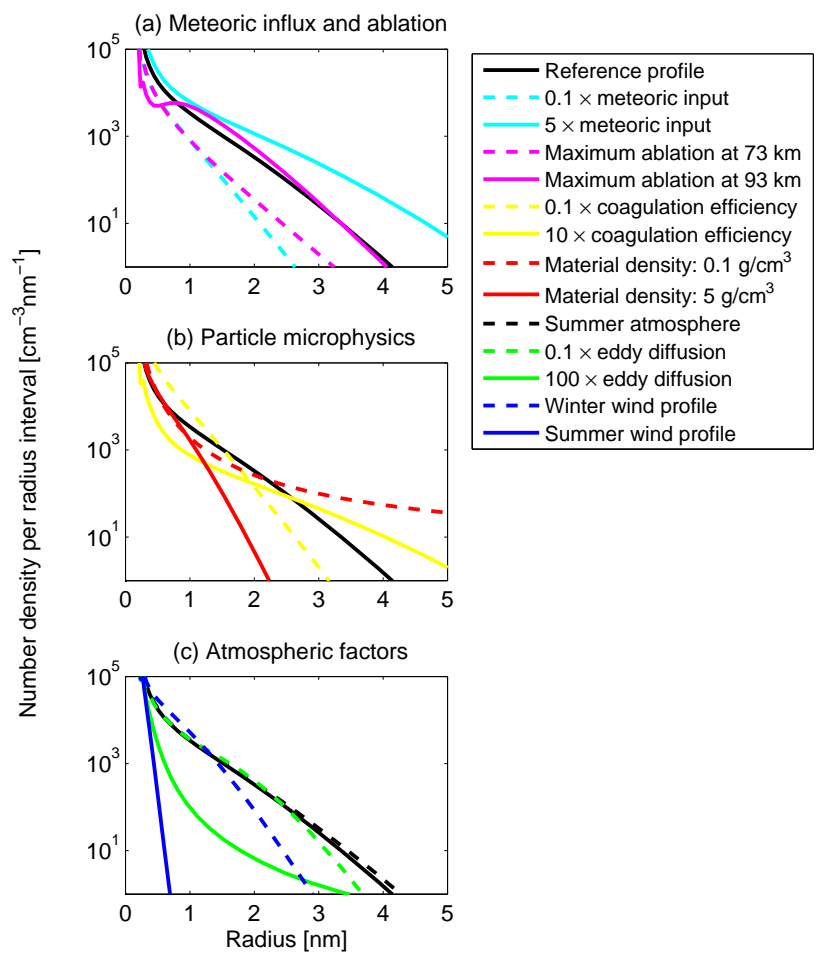

Fig. 5. Sensitivity of smoke size distribution as result of uncertainty and variability in the studied factors. The values are averages between 80 and $90 \mathrm{~km}$. The top panel shows effects due to uncertainties in meteoric input; the light blue line representing the amount of input and the magenta lines the altitude of the ablation. The middle panel shows the effects of internal smoke factors, yellow being the effects of coagulation uncertainties and red those of density/shape uncertainties. The bottom panel shows the effect of atmospheric factors, dashed black line represents summer temperatures and densities, green line shows uncertainties due to eddy diffusion and blue lines show variations due to the vertical wind.

thermodynamic conditions of the mesopause region is poor, and, therefore, this is the only feasible approach to handle nucleation of ice particles in the mesopause region.

Figure 5 shows the size distribution averaged between 80 and $90 \mathrm{~km}$. As we can see the number density decreases rapidly with size so that only 4 percent of the particles are bigger than $1 \mathrm{~nm}$. However, these particles make up $96 \%$ of the mass.

In the following sensitivity study the input variables have been varied within geophysically reasonable limits. These limits are based either on theoretical arguments or on measurements, as described in each section. The effect that each input variable has on the smoke distribution is then studied by comparing the perturbed profile to that of the reference case.

\subsection{Amount of meteoric material}

The estimates of how much meteoric material enters the earth's atmosphere vary from 5 to 400 tons/day (Gabrielli et al., 2004; Love and Brownlee, 1993; Mathews et al., 2001; Ceplecha et al., 1998). There are two reasons for this wide spread of estimates. The first is the problems involved in measuring this quantity and the second is that different measurement techniques are sensitive to different size ranges of incoming meteoroids. For studies concerned with the meteoric smoke only the meteoric material that ablates and thus stays in the atmosphere is of interest. As mentioned earlier the smallest particles do not ablate and the biggest impacts are very rare and the involved meteoroids do not fully ablate. Within the remaining size range of meteoroids the mass distribution peaks around $10^{-5} \mathrm{~g}$ (Flynn, 2002) and as much as $80 \%$ of the incoming mass originates from meteoroids of sizes between $10^{-7} \mathrm{~g}$ and $10^{-3} \mathrm{~g}$ (von Zahn, 2005). Hence, for atmospheric studies, it is enough to consider this mass range. Estimates of the mass flux within this mass range varies with almost an order of magnitude. To study the influence of the amount of meteoric material on the smoke distribution we have multiplied our original ablation profile (44 tons/day) with factors $\mathrm{f}=0.1$ and $\mathrm{f}=5$, respectively. The influence on the steady state smoke distribution is shown as light blue dashed ( $\mathrm{f}=0.1$ ) and solid lines ( $\mathrm{f}=5$ ) in Figs. 4 and 5. We see that a multiplication of the meteoric input by a factor of 5 only corresponds to a doubling of the total number densities at $80-90 \mathrm{~km}$. The changes in number densities of particles bigger than $1 \mathrm{~nm}$ radius are similar. Studying the mass density, we see that a change in meteoric input has less effect at the higher altitudes than at lower altitudes. This is due to the fact that more ablated material results in more coagulation which in turn makes the particles sediment faster. This coagulation effect can also be seen in the size distribution in Fig. 5, where an increase in meteoric input results in greater amounts of large particles.

\subsection{Height of maximum ablation}

The velocity of the incoming meteoroids determine the altitude at which the ablation occurs; a faster meteoroid experience a faster de-acceleration once it reaches the atmosphere and thus ablates at a higher altitude. The minimum meteoroid velocity is that of free fall, i.e., $11.2 \mathrm{~km} / \mathrm{s}$. Such a meteoroid would experience maximum ablation at $80 \mathrm{~km}$ (Hunten et al., 1980). The mean velocity of the incoming meteoroids is not very well known, estimates lie between $14 \mathrm{~km} / \mathrm{s}$ (Kalashnikova et al., 2000) and $24 \mathrm{~km} / \mathrm{s}$ (Taylor, 1995). This corresponds to an uncertainty in the height of ablation of about $10 \mathrm{~km}$ (Hunten et al., 1980). The effect of the velocity uncertainty was therefore studied by simply shifting the original ablation profile, which has a maximum around $83 \mathrm{~km}, 10 \mathrm{~km}$ upwards respectively downwards. The resulting smoke distributions are shown as magenta lines in Figs. 4 and 5, the 
solid line representing the upward shift and the dashed line the downward shift. We conclude that the ablation altitude has little effect on the total size distribution apart from the obvious effect that the whole distribution is shifted accordingly. Looking at the number densities of particles bigger than $1 \mathrm{~nm}$ radius and the mass density, we find that only the upper part of the distribution is altered (i.e., above $75 \mathrm{~km}$ ), while the lower part of the distribution remains almost unchanged. Recent studies indicate that meteoric ablation may occur at even higher altitudes, peaking as high as $105 \mathrm{~km}$ (Janches et al., 2003). We have investigated the effects of such a high ablation and found little difference between the resulting distribution and the solid magenta lines in Figs. 4 and 5, except that the distribution of the smallest particles, is shifted to a higher altitude.

\subsection{Coagulation efficiency}

As mentioned in Sect. 3 the model assumes spherical particle-coagulation due to Brownian motion. This is a reasonable assumption when no intra-particle forces are present, so that particles can be assumed to undergo stochastic growth, during which the particles develop toward spheres. If intra-particle forces existed or if the particle shape were non-spherical, this assumption would be a strong oversimplification. Particle charging may effectively shut off coagulation if all particles are equally charged (Jensen and Thomas, 1991), or significantly enhance coagulation if they are oppositely charged (Reid, 1997). Both these cases can be feasible in the atmosphere depending on the ratio of particle number density to the local plasma number density and, hence, on time of day, altitude, latitude, solar activity and other factors. Further, the model assumes that particles stick once they have collided. The efficiency with which nanometre dust particles stick to each other is however uncertain. If this sticking probability is much less than unity this would result in a lower coagulation efficiency.

We estimate the uncertainty of the global average of the coagulation efficiency by varying the coagulation rate between 0.1 and 10 times the nominal value. The result can be seen as yellow lines in Figs. 4 and 5 where the dashed lines show the low coagulation rate and the solid lines the high rate. As expected, we get a lower total number density with stronger coagulation (Fig. 4d). More surprisingly, we also get a lower number density of the particles bigger than $1 \mathrm{~nm}$ radius (Fig. 4e). The reason is that enhanced coagulation favours the creation of particles of even bigger sizes. Indeed for particles bigger than $7 \mathrm{~nm}$ radius, we do get an enhanced number density as a result of increased coagulation. Studying the mass density (Fig. 4f) we can see a slight decrease with increasing coagulation efficiency due to the fact that more coagulation results in bigger particles that sediment more rapidly. This shift towards bigger particles can also be seen in the size distribution at 80-90 km shown in Fig. 5.

\subsection{Density and shape of the particles}

The majority of the meteorites, i.e. the meteoric rocks found on the ground, have bulk densities of around $2-4 \mathrm{~g} / \mathrm{cm}^{3}$ (Consolmagno et al., 2006). Although this value probably well represents the incoming meteoroids it might not be representative for meteoric smoke particles. Once the smoke particles have formed, the nature of the coagulation process determines the shape of the particles. This may be anything form solid spheres (which is what we assume for our reference scenario) to fluffy aggregates or needle-like particles. The shape of the particles determines the sedimentation speed and coagulation kernels (see Table 1 in Turco et al., 1982, and the corresponding discussion of their Eqs. 8-11). As a first approximation we simulate the sedimentation speed effect simply by varying the density of the particles. The red lines in Figs. 4 and 5 represents the effect on the smoke distributions when the original density of $2 \mathrm{~g} / \mathrm{cm}^{3}$ is increased to $5 \mathrm{~g} / \mathrm{cm}^{3}$ (solid lines) and reduced to $0.2 \mathrm{~g} / \mathrm{cm}^{3}$ (dashed lines). As expected, denser smoke material results in a smoke distribution at lower altitudes (see Fig. 4d). This effect is even more pronounced for the particles bigger than $1 \mathrm{~nm}$ radius (see Fig. 4e). The density of the material has however little effect on the maximum number density. It also has little effect on the mass density (Fig. 4e). This slightly counterintuitive fact is explained by a rapid decrease of the bigger particles ( $\gtrsim 3 \mathrm{~nm}$ radius) which sediment out of the domain. The enhanced sedimentation rate associated with a higher material density leads to a reduction of the bigger particles at the mesopause, as can be seen in Fig. 5 b.

\subsection{Background state of the atmosphere}

The background state of the atmosphere can in principle influence the particle evolution as e.g. fall speed and coagulation depend on density and temperature. For our reference profile we used number densities and temperatures taken from the U.S. standard atmosphere which is an annual and global average. The real temperature varies with season and latitude and reaches its extreme values at the poles with a summer-winter difference of nearly $100 \mathrm{~K}$ at the mesopause (e.g. Lübken and von Zahn, 1991). To study the effects of the background atmosphere we therefore used summer temperatures and densities taken from the CHEM2D model (Summers et al., 1997). This temperature distribution is shown as a dashed line in Fig. 3, where the solid line shows the U.S. standard atmosphere. The densities are of course connected to the temperatures and the greatest relative differences between the U.S. standard atmosphere and the summer CHEM2D profile are found around $100 \mathrm{~km}$ and amount to a factor two. The effect of the background atmosphere on the smoke distributions is shown as black dashed lines in Figs. 4 and 5. The effect is miniscule and it is hard to separate the dashed line from the underlying solid black line of the reference profile. 
Table 1. Sensitivity of number or column densities due to two different factors. The values are relative to the reference case so that a 2 means twice as high density as the reference profile. (A) the average total number density between 80 and $90 \mathrm{~km}$ (B) the average number densities of particles bigger than $1 \mathrm{~nm}$ between 80 and $90 \mathrm{~km},(\mathrm{C})$ the total column density and (D) the column density of particles bigger than $1 \mathrm{~nm}$ radius.

\begin{tabular}{|c|c|c|c|c|c|c|c|}
\hline & $\begin{array}{l}\text { Meteoric } \\
\text { input }\end{array}$ & $\begin{array}{c}\text { Height of } \\
\text { maximum ablation }\end{array}$ & $\begin{array}{l}\text { Atmospheric state } \\
\text { eddy diffusion }\end{array}$ & Vertical & $\begin{array}{l}\text { Coagulation } \\
\text { density }\end{array}$ & $\begin{array}{l}\text { Material } \\
\text { wind }\end{array}$ & Vertical \\
\hline $\begin{array}{l}\text { Meteoric } \\
\text { input }\end{array}$ & $\begin{array}{l}0.3<\mathrm{A}<2.1 \\
0.1<\mathrm{B}<2.6 \\
0.3<\mathrm{C}<2.1 \\
0.4<\mathrm{D}<1.8\end{array}$ & $\begin{array}{l}0.3<\mathrm{C}<2.3 \\
0.3<\mathrm{D}<2.8\end{array}$ & $\begin{array}{l}0.3<\mathrm{A}<2.3 \\
0.1<\mathrm{B}<2.7 \\
0.3<\mathrm{C}<2.3 \\
0.4<\mathrm{D}<1.9\end{array}$ & $\begin{array}{c}0.1<\mathrm{A}<2.2 \\
0.003<\mathrm{B}<2.7 \\
0.3<\mathrm{C}<3.4 \\
0.3<\mathrm{D}<2.4\end{array}$ & $\begin{array}{c}0.1<\mathrm{A}<7.3 \\
0.04<\mathrm{B}<6.0 \\
0.1<\mathrm{C}<7.2 \\
0.1<\mathrm{D}<7.6\end{array}$ & $\begin{array}{c}0.3<\mathrm{A}<3.3 \\
0.003<\mathrm{B}<2.6 \\
0.3<\mathrm{C}<3.4 \\
0.2<\mathrm{D}<2.1\end{array}$ & $\begin{array}{c}0.1<\mathrm{A}<2.2 \\
10^{-5}<\mathrm{B}<3.5 \\
0.1<\mathrm{C}<2.3 \\
10^{-5}<\mathrm{D}<6.8\end{array}$ \\
\hline $\begin{array}{l}\text { Height of } \\
\text { maximum ablation }\end{array}$ & & $\begin{array}{l}0.9<\mathrm{C}<1.1 \\
0.7<\mathrm{D}<1.4\end{array}$ & $\begin{array}{l}0.9<\mathrm{C}<1.2 \\
0.7<\mathrm{D}<1.4\end{array}$ & $\begin{array}{l}0.9<\mathrm{C}<1.9 \\
0.6<\mathrm{D}<1.4\end{array}$ & $\begin{array}{l}0.3<\mathrm{C}<3.8 \\
0.2<\mathrm{D}<4.0\end{array}$ & $\begin{array}{l}0.8<\mathrm{C}<1.7 \\
0.4<\mathrm{D}<1.4\end{array}$ & $\begin{array}{c}0.5<\mathrm{C}<1.4 \\
10^{-5}<\mathrm{D}<6.6\end{array}$ \\
\hline $\begin{array}{l}\text { Atmospheric } \\
\text { state }\end{array}$ & & & $\begin{array}{l}1.0<\mathrm{A}<1.1 \\
1.0<\mathrm{B}<1.1 \\
1.0<\mathrm{C}<1.1 \\
1.0<\mathrm{D}<1.0\end{array}$ & $\begin{array}{c}0.7<\mathrm{A}<1.1 \\
0.02<\mathrm{B}<1.2 \\
1.0<\mathrm{C}<1.7 \\
0.9<\mathrm{D}<1.2\end{array}$ & $\begin{array}{l}0.3<\mathrm{A}<3.7 \\
0.4<\mathrm{B}<1.5 \\
0.3<\mathrm{C}<3.7 \\
0.2<\mathrm{D}<3.7\end{array}$ & $\begin{array}{l}0.9<\mathrm{A}<1.8 \\
0.2<\mathrm{B}<1.3 \\
0.9<\mathrm{C}<1.8 \\
0.6<\mathrm{D}<1.0\end{array}$ & $\begin{array}{c}0.7<\mathrm{A}<1.2 \\
10^{-5}<\mathrm{B}<1.1 \\
0.8<\mathrm{C}<1.4 \\
10^{-5}<\mathrm{D}<5.6\end{array}$ \\
\hline $\begin{array}{l}\text { Vertical eddy } \\
\text { diffusion }\end{array}$ & & & & $\begin{array}{c}0.7<\mathrm{A}<1.0 \\
0.02<\mathrm{B}<1.2 \\
1.0<\mathrm{C}<1.7 \\
0.9<\mathrm{D}<1.2\end{array}$ & $\begin{array}{c}0.2<\mathrm{A}<3.5 \\
0.02<\mathrm{B}<1.6 \\
0.2<\mathrm{C}<5.5 \\
0.2<\mathrm{D}<3.8\end{array}$ & $\begin{array}{c}0.4<\mathrm{A}<1.9 \\
0.01<\mathrm{B}<1.4 \\
0.8<\mathrm{C}<2.5 \\
0.6<\mathrm{D}<2.1\end{array}$ & $\begin{array}{c}0.6<\mathrm{A}<1.1 \\
10^{-5}<\mathrm{B}<1.1 \\
0.7<\mathrm{C}<1.8 \\
10^{-5}<\mathrm{D}<5.8\end{array}$ \\
\hline Coagulation & & & & & $\begin{array}{l}0.3<\mathrm{A}<3.5 \\
0.4<\mathrm{B}<1.3 \\
0.3<\mathrm{C}<3.5 \\
0.2<\mathrm{D}<3.6\end{array}$ & $\begin{array}{c}0.3<\mathrm{A}<5.6 \\
0.03<\mathrm{B}<4.7 \\
0.3<\mathrm{C}<5.8 \\
0.2<\mathrm{D}<3.8\end{array}$ & $\begin{array}{c}0.3<\mathrm{A}<4.6 \\
10^{-5}<\mathrm{B}<1.3 \\
0.3<\mathrm{C}<7.7 \\
10^{-5}<\mathrm{D}<29\end{array}$ \\
\hline $\begin{array}{l}\text { Material } \\
\text { density }\end{array}$ & & & & & & $\begin{array}{l}0.9<\mathrm{A}<1.6 \\
0.2<\mathrm{B}<1.3 \\
0.9<\mathrm{C}<1.7 \\
0.6<\mathrm{D}<1.0\end{array}$ & $\begin{array}{c}0.4<\mathrm{A}<2.0 \\
10^{-5}<\mathrm{B}<2.1 \\
0.4<\mathrm{C}<2.0 \\
10^{-5}<\mathrm{D}<5.6\end{array}$ \\
\hline $\begin{array}{l}\text { Vertical } \\
\text { wind }\end{array}$ & & & & & & & $\begin{array}{c}0.7<\mathrm{A}<1.1 \\
10^{-5}<\mathrm{B}<1.0 \\
0.8<\mathrm{C}<1.3 \\
10^{-5}<\mathrm{D}<5.6\end{array}$ \\
\hline
\end{tabular}

\subsection{Eddy diffusion}

In order to parameterise atmospheric motions which cannot be resolved by a particular model (like e.g., small scale waves and turbulence), the concept of eddy-diffusion is usually applied in which these non-resolved parts of the atmospheric flow are simply treated as a diffusive process. Hence, profiles of eddy-diffusion coefficients cannot be directly measured, but must be inferred through a combination of modelling and measurements of e.g. the vertical distribution of trace constituents (Chabrillat et al., 2002). This results in a wide range of estimates; the maximum mesospheric vertical eddy diffusion ranges from $10 \mathrm{~m}^{2} / \mathrm{s}$ (CHEM2D model average over latitudes and seasons) to $1000 \mathrm{~m}^{2} / \mathrm{s}$ (Hocking, 1990). To reflect this spread we have multiplied our initial eddy diffusion profile which peaks at $10 \mathrm{~m}^{2} / \mathrm{s}$ (see Fig. 3) with a factor 100 . The result on the smoke distribution is shown by the solid green line in Figs. 4 and 5. Eddy diffusion acts to spread the particles over a larger altitude interval. The effects are seen in the total number densities (Fig. 4g), in the number densities of particles bigger than $1 \mathrm{~nm}$ radius (Fig. 4h) as well as in the mass density (Fig. 4i). Since our reference case is at the lower end of the estimated eddy diffusion profile, a further reduction of the eddy diffusion has little effect. That can be seen by the dashed green lines in Figs. 4 and 5, which show the resulting smoke distribution when the eddy diffusion profile was divided by 10 .

\subsection{Vertical wind profile}

The mesospheric residual circulation is characterised by strong up-draught at the summer pole, transport towards the winter hemisphere and down-draught at the winter pole. The extreme vertical wind profiles as computed by the CHEM2D model (Summers et al., 1997) are shown in Fig. 3d, where the dashed line is appropriate for northern hemispheric summer conditions, and the dashed-dotted line shows the corresponding winter profile. Using these two profiles as vertical wind input we obtain the smoke distributions seen as blue lines in Figs. 4 and 5, the solid line corresponding to the summer 
profile and the dashed line to the winter profile. We notice that the winds have little effect on the total smoke number densities between 80 and $100 \mathrm{~km}$ (Fig. 4g). However, studying particles bigger than $1 \mathrm{~nm}$ radius, the effect becomes dramatic (see Fig. 4h). In the winter we expect an enhanced distribution (dashed line) whereas in summer the number densities are reduced to less than 1 particle $/ \mathrm{cm}^{3}$ (the solid line can thus not be seen in the figure). The effect of the vertical wind on the mass densities can be understood as a combination of these effects; the winter profile showing only a little effect whereas the summer winds lead to a strong reduction due to the loss of bigger particles.

\subsection{Summary of sensitivities}

In order to easily compare the effects of the different factors, we have studied the change in column density, i.e. the vertically integrated number of particles in the model domain. Even though the model domain spans all the way from $10 \mathrm{~km}$ to $110 \mathrm{~km}$, this quantity represents the mesospheric conditions, since the column density is completely dominated by particles above the stratopause. The change in column density, relative to our reference case, is presented in Fig. 6. The upper panel shows the effect on the column density of all particles, the lower panel shows the column density of particles bigger than $1 \mathrm{~nm}$ radius. We see that the uncertainty in coagulation efficiency induces the greatest uncertainties in the total column density, ranging from 0.3 to 3.5 times that of the reference profile. Looking at the particles bigger than $1 \mathrm{~nm}$ radius we see that the variation in the vertical wind can cause the column density to vary from less than $10^{-5}$ (i.e., essentially zero) to 5.6 times that of the reference case with no wind, and that the coagulation efficiency induces the second greatest uncertainties, between 0.2 and 3.6 times those of the reference profile.

Figure 6 thus summarises the influence of each individual factor on the smoke distribution. However, the combined effect of two or more factors may be significantly larger. In order to address this issue we also studied the combined effect of two simultaneously altered factors on the smoke distribution. To do this in a systematic way we concentrated on a few relevant quantities; (A) the average total number density between 80 and $90 \mathrm{~km}$ (B) the average number density of particles larger than $1 \mathrm{~nm}$ between 80 and $90 \mathrm{~km}$, (C) the total column density and (D) the column density of particles bigger than $1 \mathrm{~nm}$ radius. The extreme values of these quantities found by systematically varying two factors at the same time are summarised in Table 1. Not surprisingly, we find that the uncertainty in coagulation efficiency and the variation of the vertical winds cause the largest combined effect; average number densities between 80 and $90 \mathrm{~km}$ of particles bigger than $1 \mathrm{~nm}$ radius range from $10^{-5}$ to 29 times that of the reference profile. For the total column density the values range from 0.3 to 7.7 times the reference case. Note that the (a)

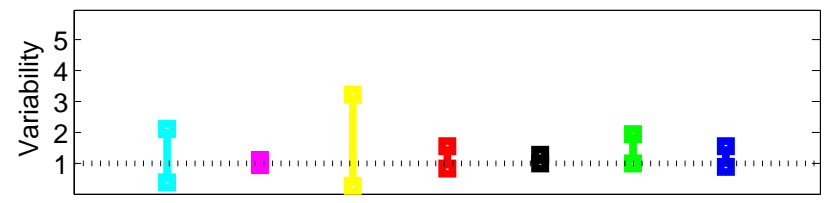

(b)

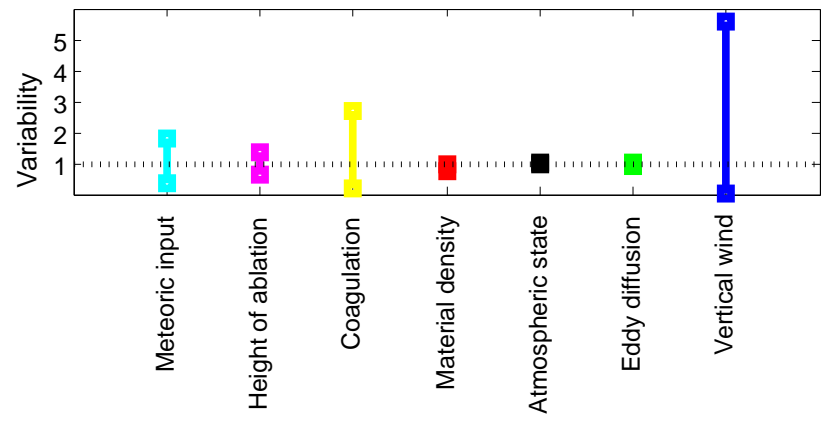

Fig. 6. Sensitivity of the column density to different factors; (a) column density of all particles and (b) column of density of particles larger than $1 \mathrm{~nm}$ radius. The variability is to be interpreted as "times the reference case".

four quantities A-D, in general show similar dependencies on the various model parameters.

It is interesting to note the non-linearity in the interactions between the factors. The extreme values of the smoke distribution (quantities A-D) do not always correspond to the extreme values of the input parameters. Further, at a certain point in parameter space two factors may enhance each other, while cancelling each other in another point. An example is the combined effect of material density and coagulation, Fig. 7. This plot shows the increase/decrease of the number density (averaged between 80 and $90 \mathrm{~km}$ ) relative to that of our reference profile as a function of the material density and the coagulation efficiency. We see that for our nominal coagulation efficiency, the total number density (Fig. 7a) varies very little with material density. However, if the coagulation efficiency is decreased the variation with material density becomes prominent. This is due to the fact that when there is little coagulation the sedimentation speed and, hence, the material density determines the particle population at the mesopause. On the other hand, when coagulation becomes more effective, the high number densities of small particles cannot be maintained and coagulation becomes the limiting factor. Figure $7 \mathrm{~b}$ shows the same dependence for particles larger than $1 \mathrm{~nm}$. Even for these particles, low coagulation is favourable. As earlier mentioned this is because stronger coagulation does not only cause more $1 \mathrm{~nm}$ particles to form but also coagulates them more efficiently to bigger sizes. 

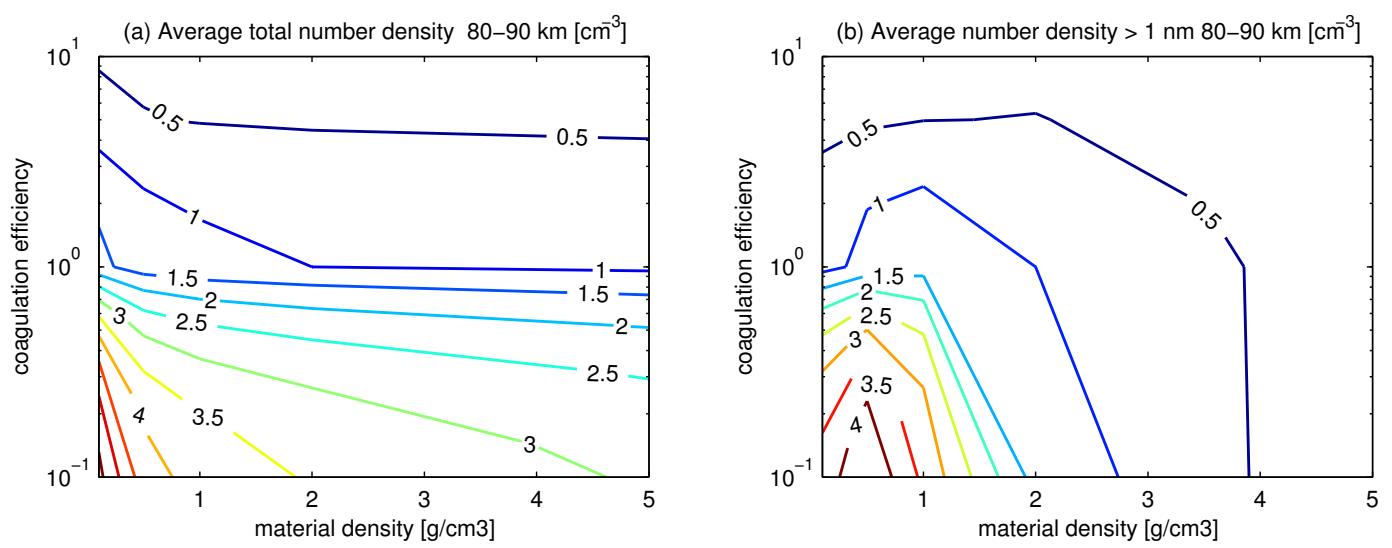

Fig. 7. Sensitivity of number density between 80 to $90 \mathrm{~km}$ to variations of coagulation and density, relative to the reference case. The values shown are to be interpreted as "times the reference profile". The value of the vertical axis is to be read as "times the nominal coagulation rate" so that 1 represents the coagulation of the reference case.

\section{Conclusions}

The sensitivities of meteoric smoke distributions have been studied with respect to a number of factors that either are poorly known or highly variable. We have shown that vertical wind and coagulation efficiency are the two unknowns that have the greatest effect on the smoke distribution. The vertical wind has little influence on the smallest particle fragments but severe effects on the distribution of particles bigger than $1 \mathrm{~nm}$ radius, i.e. the particles that are thought to serve as nucleation seeds for noctilucent clouds. The winter down-draught enhances the particle distribution by a factor 6 while the summer up-draught drastically reduces the number of particles at the summer mesopause so that less than one potential ice nuclei per cubic centimetre remains.

This result is puzzling considering that of the order of 100 particles $\mathrm{cm}^{-3}$ are believed to be required to produce polar mesospheric summer echoes and noctilucent clouds. If indeed there were only 1 particle $\mathrm{cm}^{-3}$, meteoric smoke could not be the only nucleation kernel for ice at the summer mesopause. However, taking all the uncertainty factors into account, it is clear that we cannot say for sure that this the case. For instance, summer up-draught in combination with a reduction of the material density to $0.1 \mathrm{~g} / \mathrm{cm}^{3}$, yields around 1000 nanometre-sized particles at the mesopause. In a similar way a $10 \mathrm{~km}$ lower ablation height and typical summer winds lead to around 100 particles of this size. Increasing either the coagulation efficiency by a factor 10 or the eddy diffusion by a factor 10 both result in around 10 particles larger than $1 \mathrm{~nm}$ radius at the summer mesopause. As we see, within the uncertainty range there are ways out of this dilemma. Further studies about the role of meteoric smoke in the nucleation of noctilucent clouds are currently under way.

Nevertheless, the effect of transport is of critical importance for the distribution and properties of both meteoric smoke particles and ice particles in the middle atmosphere. This result relies on the assumption that the outward diffusion of the meteor tail is high enough so that little or no coagulation takes place within the meteor tail, as argued in Plane (2000). Should the initial growth to $1 \mathrm{~nm}$ particles prove to be much faster than currently thought (for instance due to strong electric or magnetic forces) this assumption may no longer be valid.

The effect of many factors has been shown to be nonlinear. For example 5 times the meteoric input into the atmosphere only results in $2-3$ times as many particles. The non-linearity of the problem becomes even clearer when the combined effects of two factors are studied. These effects can often greatly outweigh the sum of the two separate effects.

In order to constrain the unknown parameters, simultaneous measurements of particle properties and background properties are important. This includes number densities, size distributions, the ratio of charged particles to neutral particles, as well as the determination of the composition of smoke particles. Measurements of number densities and size distributions would allow us to deduce constrains of the factors related to smoke production as long as the atmospheric environment is reasonably well known. Knowledge of the composition of meteoric smoke would significantly reduce the uncertainties in both material density and coagulation efficiency. An attempt to study smoke composition has recently been made by the means of rockets-borne collection and subsequent laboratory analysis (Gumbel, 2005). The results from these campaigns are still waiting to be published. Measurements of the ratio of charged to neutral particles would give considerate constrains on the coagulation efficiency. Efforts to measure this ratio are currently under way in the framework of the German-Norwegian-led ECOMAproject (Rapp et al., 2003). 
The importance of the vertical wind, and the resulting variations in smoke distribution, need to be considered when comparing data from rocket campaigns to model results. U1timately, a series of rocket measurements performed at different seasons, would be needed to validate our understanding of the role of meteoric smoke in the middle atmosphere.

When it comes to modelling, it is important to investigate the effects of transport in a 2- or 3-dimensional model. A one-dimensional model treats the transport in a simplistic way, as described in Sect. 3. Hence, these results must be confirmed by coupling a microphysical model of smoke formation and evolution with an appropriate 2-D or 3-D circulation model of the atmosphere. With such a model, spatial and temporal variations in the smoke distribution could be properly studied, which would enable better comparisons with experiments.

Acknowledgements. The authors would like to thank J. Plane for fruitful discussions, and D. Siskind for making the CHEM2D model available. M. Rapp appreciates the support of the Deutsche Forschungsgemeinschaft (DFG) under grant RA 1400/2-1.

Edited by: B. Kärcher

\section{References}

Ceplecha, Z., Borovicka, J., Elford, W. G., Revelle, D. O., Hawkes, R. L., Porubcan, V., and Simek, M.: Meteor phenomena and bodies, Space Sci. Rev., 84, 327-471, 1998.

Chabrillat, S., Kockarts, G., Fonteyn, D., and Brasseur, G.: Impact of molecular diffusion on the $\mathrm{CO}_{2}$ distribution and the temperature in the mesosphere, Geophys. Res. Lett., 29, 1729-1732, 2002.

Colela, P. and Woodard, P. R.: The piecewise parabolic method (PPM) for gas-dynamical simulations, J. Comput. Phys., 54, 174-201, 1984.

Consolmagno, G. J., Macke, R. J., Rochette, P., Britt, D. T., and Gattacceca, J.: Density, magnetic susceptibility, and the characterization of ordinary chondrite falls and showers, Meteorit. Planet. Sci., 41, 331-342, 2006.

Croskey, C., Mitchell, J., Friedrich, M., Torkar, K., Hoppe, U.-P., and Goldberg, R.: Electrical structure of PMSE and NLC regions during the DROPPS program, Geophys. Res. Lett., 28, 14271430, 2001

Flynn, G. J.: Meteors in the Earth's Atmosphere, Cambridge Univ. Press, 2002.

Fuchs, N. A.: The mecheancs of aerosols, Pergamon Press, New York, 1964.

Gabrielli, P., Barbante, C., Plane, J. M. C., Varga, A., Hong, S., Cozzi, G., Gasparia, V., Planchon, F. A. M., Cairns, W., Ferrari, C., Crutzen, P., Ceson, P., and Boutron, C. F.: Meteoric smoke fallout over the holocene epoch revealed by iridium and platinum in Greenland ice, Nature, 432, 1011-1014, 2004.

Gelinas, L. J., Lynch, K. A., Kelley, M. C., Collins, S., Baker, S., Zhou, Q., and Friedman, J. S.: First observation of meteoritic charged dust in the tropical mesosphere, Geophys. Res. Lett., 25, 4047-4050, 1998.
Gray, R. W.: Disperse Systems in Gases, Trans. Faraday Soc., 32, 1041 pp., 1936.

Gumbel, J.: The MAGIC rocket campaign - an overview, Proceedings of the 17th ESA Symposium on European Rocket and Balloon Programmes and Related Research, Sandefjord, Norway (ESA SP-590), 139-144, 2005.

Hocking, W.: Turbulence in the region $80-120 \mathrm{~km}$, Adv. Space Res., 10, 153-161, 1990.

Hunten, D. M., Turco, R. P., and Toon, O. B.: Smoke and Dust Particles of Meteoric Origin in the Mesosphere and Stratosphere, J. Atmos. Sci., 37, 1342-1357, 1980.

Jacobson, M. Z., Lu, R., Jensen, E. J., and Toon, O. B.: Modelling coagulation among particles of different composition and size, Atmos. Environ, 28, 1327-1338, 1994.

Janches, D., Nolan, M. C., Meisel, D. D., Mathews, J. D., Zhou, Q. H., Moser, D. E.: On the geocentric micrometeor velocity distribution, J. Geophys. Res., 108(A6), 1222, doi:10.1029/JA009789, 2003.

Jensen, E. and Thomas, G. E.: Charging of mesospheric particles: implications of electron density and particle coagulation, J. Geophys. Res., 96, 18 603-18 615, 1991.

Jensen, E., Thomas, G. E., and Toon, O. B.: On the diurnal variation of noctilucent clouds, J. Geophys. Res., 94, 14 693-14 702, 1989.

Jensen, E. J., Toon, O. B., Vay, S. A., Ovarlez, J., May, R., Bui, T. P., Twohy, C. H., Gandrud, B. W., and Schumann, R. F. P. U.: Prevalence of ice-supersaturated regions in the upper troposphere: Implications for optically thin ice cloud formation, J. Geophys. Res., 106, 17 253-17 266, 2001.

Kalashnikova, O., Hornayi, M., Thomas, G. E., and Toon, O. B.: Meteoric smoke production in the atmosphere, Geophys. Res. Lett., 27, 3293-3296, 2000.

Keesee, R. G.: Nucleation and particle formation in the upper atmosphere, J. Geophys. Res., 94, 14 683-14692, 1989.

Love, S. G. and Brownlee, D. E.: A direct measurement of the terrestrial mass accretion rate of cosmic dust, Science, 262, 550 553, 1993.

Lübken, F.-J. and von Zahn, U.: Thermal structure of the mesopause region at polar latitudes, J. Geophys. Res., 96, 20 841-20 857, 1991.

Lynch, K. A., Gelinas, L. J., Kelley, M. C., Collins, R. L., Widholm, M., Rau, D., MacDonald, E., Liu, Y., Ulwick, J., and Mace, P.: Multiple sounding rocket observations of charged dust in the polar winter mesosphere, J. Geophys. Res., 110, A03302, doi:10.1029/2004JA010502, 2005.

Mathews, J. D., Janches, D., Meisel, D. D., and Zhou, Q. H.: The micrometeoroid mass flux into the upper atmosphere: Arecibo results and comparision with prior estimates, Geophys. Res. Lett., 28, 1929-1932, 2001.

Millikan, R. A.: The general law of fall of a small spherical body through a gas, and its bearing upon the nature of molecular reflection from surfaces, Phys. Rev., 22, 1-23, 1923.

Plane, J. M. C.: The role of sodium bicarbonate in the nucleation of noctilucent clouds, Ann. Geophys., 18, 807-814, 2000, http://www.ann-geophys.net/18/807/2000/.

Plane, J. M. C.: Atmospheric chemistry of meteoric metals, Chem. Rev, 103, 4963-4984, 2003. 
Plane, J. M. C.: A time-resolved model of the mesospheric Na Layer: constraints on the meteor input function, Atmos. Chem. Phys., 4, 627-638, 2004, http://www.atmos-chem-phys.net/4/627/2004/.

Pruppacher, H. R. and Klett, J. D.: Microphysics of clouds and precipitation, Kluwer academic publishers, Dordrecht, The Netherlands, 1997.

Rapp, M. and Lübken, F.-J.: Polar mesosphere summer echoes (PMSE): Review of observations and current understanding, Atmos. Chem. Phys., 4, 2601-2633, 2004, http://www.atmos-chem-phys.net/4/2601/2004/.

Rapp, M. and Thomas, G. E.: Modeling the microphysics of mesospheric ice particles - Assessment of current capabilities and basic sensitivities, J. Atmos. Sol. Terr. Phys., 68, 715-744, 2006.

Rapp, M., Strelnikov, B., Wilms, S., Lübken, F.-J., Gumbel, J., and Henkel, H.: A new detector for the in situ measurement of meteoric dust particles in the middle atmosphere, Proceedings of the 16th ESA Symposium on European Rocket and Balloon Programmes and Related Research, St. Gallen, Switzerland (ESA SP-530), 379-384, 2003.

Rapp, M., Hedin, J., Strelnikova, I., Friedrich, M., Gumbel, J., and Lübken, F.-J.: Observations of positively charged nanoparticles in the nighttime polar mesosphere, Geophys. Res. Lett., 32, L23821, doi:10.1029/2005GL024676, 2005.

Reid, G. C.: On the influence of electrostatic charging on coagulation of dust and ice particles in the upper mesosphere, Geophys. Res. Lett., 24, 1095-1098, 1997.

Rosinski, J. and Snow, R. H.: Secondary particulate matter from meteor vapors, J. Meteorol., 18, 736-745, 1961.

Schulte, P. and Arnold, F.: Detection of upper atmospheric negatively charged microclusters by a rocket borne mass spectrometer, Geophys. Res. Lett., 19, 2297-2300, 1992.
Summers, M. E. and Siskind, D. E.: Surface recombination of $\mathrm{O}$ and $\mathrm{H} 2$ on meteoric dust as a source of mesospheric water vapour, Geophys. Res. Lett., 26, 1837-1840, 1999.

Summers, M. E., Siskind, D. E., Bacmeister, J. T., Conway, R. R., Zasadil, S. E., and Strobel, D. F.: Seasonal variation of middle atmospheric $\mathrm{CH}_{4}$ and $\mathrm{H}_{2} \mathrm{O}$ with a new chemical dynamical model, J. Geophys. Res., 102, 3503-3526, 1997.

Taylor, A. D.: The Harvard radio meteor project meteor velocity distribution reappraised, Icarus, 116, 154-158, 1995.

Toon, O. B., Turco, R. P., Hamill, P., Kiang, C. S., and Whitten, R. C.: A one dimensional model describing aerosol formation and evolution in the stratosphere, II. Sensitivity studies and comparison with observations., J. Atmos. Sci., 36, 718-736, 1979.

Toon, O. B., Turco, R. P., Westphal, D., Malone, R., and Liu, M. S.: A multidimensional model for aerosols: description and computational analogs, J. Atmos. Sci., 45, 2123-2143, 1988.

Toon, O. B., Turco, R. P., Jordan, J., Goodman, J., and Ferry, G.: Physical processes in polar stratospheric clouds, J. Geophys. Res., 94, 11 359-11380, 1989.

Turco, R. P., Hamill, P., Toon, O. B., Whitten, R. C., and Kiang, C. S.: A one dimensional model describing aerosol formation and evolution in the stratosphere, I. Physical processes and mathematical analogs., J. Atmos. Sci., 36, 699-717, 1979.

Turco, R. P., Toon, O. B., Whitten, R. C., Keesee, R. G., and Hollenbach, D.: Noctilucent Clouds: Simulation Studies of their Genesis, Properties and Global Influences, Planet. Space Sci., 3, 1147-1181, 1982.

von Zahn, U.: The total mass flux of meteoroids into the Earth's upper atmosphere, Proceedings of the 17th ESA Symposium on European Rocket and Balloon Programmes and Related Research, Sandefjord, Norway (ESA SP-590), 33-39, 2005.

Witt, G.: The nature of noctilucent clouds, Space Res., IX, 157169, 1969. 